\title{
Seymour Cray: The Father of World Supercomputer
}

\author{
Si Hongwei \\ Department of the History of Science, Tsinghua University, Beijing, China \\ Email address: \\ howes@mail.tsinghua.edu.cn \\ To cite this article: \\ Si Hongwei. Seymour Cray: The Father of World Supercomputer. History Research. Vol. 7, No. 1, 2019, pp. 1-6. \\ doi: 10.11648/j.history.20190701.11
}

Received: May 14, 2019; Accepted: June 13, 2019; Published: June 26, 2019

\begin{abstract}
Seymour R. Cray was an American engineer and supercomputer developer who designed a series of the fastest computers in the world in 1960-1980s. The difference between Cray and most other corporate engineers is that he often won those business battles. His success was attributable to his existence in a postwar culture where engineers were valued. He was able to also part of an extraordinary industry where revolutionary developments were encouraged, and even necessary. Lastly Cray is recognized as "the father of world supercomputer". From the perspective of science and technology history, this paper describes the history of Cray and his development of supercomputer. It also sums up his innovative ideas and scientific spirit. It provides a reference for supercomputer enthusiasts and peers in the history of computer research.
\end{abstract}

Keywords: Seymour R. Cray, Supercomputer, Science and Technology History

\section{Introduction}

Supercomputer refers to the most advanced electronic computer system with the most advanced technology, the fastest computing speed, the largest storage capacity and the highest level of science and engineering under the current production process conditions. Supercomputers are usually composed of multiple or even hundreds of CPU, with huge numerical computing power and data processing capabilities, and can calculate large and complex problems that ordinary personal computers and servers cannot accomplish. Supercomputers are widely used in the most advanced fields of science and technology, industry, military, etc. The development capability of supercomputers has become one of the most important indicators for measuring the comprehensive national strength and technological level of a country. The world who first proposed the concept of supercomputer has been unable to verify, but in the true sense, the first person to develop a supercomputer-defined product is Seymour Roger Cray (1925-1996), who developed Cray supercomputers. For the representative of the "Cray" series of the world's fastest supercomputer, leading the international supercomputer development trend for decades, he is indisputably known as the "father of the world supercomputer."[1]

\section{The Genius Seymour}

Seymour Cray was born on September 28th, 1925 in the town of Chippewa, Wisconsin. As the same name as Seymour R. Cray, his father graduated from the University of Minnesota and worked as an engineer at northern States. At that time, the local power supply was mainly from hydro-power. The Chippewa River flows through Wisconsin and Minnesota and merges into the Mississippi River to the south. Northern State Power Company built some dams on the river to get the most electricity. The elder Cray was sent to Wisconsin in order to service the dam and determine engineering problems such as storage. He loved the job very much and accomplished his mission brilliantly. Being appointed by local officials as an engineer, Cray stayed in the town and continued his work in order to raise a family.

The elder Cray was a smart, tough, disciplinarian who'd brought up his two children as mirror images of himself. Father's obsession with technology and the pursuit of perfection had a big influence on the young Seymour, which made him fascinated by electronics from an early age. Captivated by technology, he found an avenue for expression in photography at age ten. He built a darkroom in the basement, snapped photos in the yard, and developed them himself. While still in elementary school, he even rigged a Morse Code connection between his bedroom and his sister's 
so that they could communicate after lights out. His father became aware of the late night clicking and told Seymour to shut down the system because it was bothering the rest of the household. Seymour's solution was to convert the clickers to lights and to continue to communicate with his sister. As an amateur of electrical equipment, he often spent a lot of time in the electrical laboratory of his high school, delving into radio, electric motors and electrical circuits. His served as electrician for the junior prom and in physics class acted as substitute teacher when the regular one called in sick. According to the yearbook of the Chippewa Falls High School, the Monocle, a classmate wrote: "As science is becoming more and more important each year, many students are needed in this field. Seymour Cray has received the science award. He has been very much interested in this work through high school days. If anyone were to predict his future, I dare say it would be along the science line."[2]

In 1943, during the Second World War, Cray joined the US Army after graduation and served as a radio operator for communications. After a short European mission, he was sent to the Philippines, where he operated his radio equipment from a cave in a remote area. At the same time, electronic computers were developed under the military needs of World War II. At that time, the US military needed a high-performance tool to calculate the timely and accurate ballistic firepower meter. In this context, the world's first computer_ENIAC (Electronic Numerical Integrator And Computer) in 1946 was successfully constructed and operated at the Moore School of Electrical Engineering, University of Pennsylvania, USA. The inventor was a research team led by Mauchly and Eckert. The famous scientist John von Neumann was also added. Cray, who was about to being discharged from the service, didn't know that he would be associated with this invention that had changed his life in the future.

In 1947, Cray married Verene, his wife, was the daughter of a Methodist minister. Soon they went to study at the University of Wisconsin. A year later, they moved to the University of Minnesota for a better engineer program. At the university where his father had studied, Cray earned a bachelor's degree in electrical engineering and a master's degree in applied mathematics during 1950-1951. When he graduated, Cray was quite awkward. He often walked around on campus and asked himself: "What should I do next?" Fortunately, like his father, he'd found his first job through a lead from an admiring professor: He had been strolling across the campus when a professor had leaned out a window and called him: "If I were you, I would not stay in the market, but go to ERA (Engineering Research Associates), which is a good place to show your talents." Developed by a former US naval laboratory, ERA was making cryptography's equipment for the military. Cray took the advice and rushed to ERA.

In 1951, Cray joined a local company of ERA. It was originally an old-fashioned glider factory in St. Paul, Minnesota. It was making some encrypt-devices for the US Navy. Cray began working on a variety of computer technologies, from vacuum tubes, magnetic amplifiers to transistors, and then to the 1100 series of computers, which became the later well-known product UNIVAC. He spent a lot of time reading books in the library to study how the computer works. He also had the opportunity to participate in ERA's academic activities and listen to Neumann's speech. However, he soon discovered that he did not have much reference material for researching computers. So, he wanted to practice and innovate himself. In order to avoid entertainment and make work undisturbed, Cray often worked at night, which became his lifelong habit. In the study, Cray paid great attention to collecting all aspects of information and learning from other computer designers.

In this small company, Cray designed his first computer-ERA 1103 - one of the earliest machines using magnetic core memory. The system used electrostatic storage, consisting of 36 Williams tubes with a capacity of 1024 bits each, giving a total random access memory of 1024 words of 36 bits each. Each of the 36 Williams tubes was five inches in diameter. A magnetic drum memory provided 16,384 words. Fixed-point numbers had a 1-bit sign and a 35-bit value, with negative values represented in ones' complement format. Instructions had a 6-bit operation code and two 15-bit operand addresses. [3]

2-3 years later, ERA was acquired by Remington Rand. Then, Sperry Corporation merged with it. Soon it was followed by Burroughs, and later by Unisys. Cray's work was not affected. However, when the company's executives shifted their focus to commercial small computers, Cray took his A-big-one dream of leaving the company. He and his friend Bill Norris and others created the CDC (Control Data Corporation) in 1957.

At CDC, Cray was a technical expert and a vice-chairman of the company. His goal was to develop a first-rate scientific computer which was faster than any computer at that time. He persuaded other top executives and took out his own $\$ 5,000$ to buy the company's stock during financial difficulties. As a result, $\mathrm{CDC}$ and Cray began building large scientific computers. They quickly took the market away from ERA and earned $\$ 600,000$.

When CDC expanded, Cray found that the staff was divergent. He moved out of the city and returned to the town of Chippewa, where he built a warehouse to develop 1604 computer for CDC. It was Cray's first project_— building a large computer as quickly as possible at the lowest price. At that time, the transistor was still a new electronic device, but Cray decided to use it to build CDC 1604. He found that the transistors sold at local retail stores in Minneapolis had defective products, which were much cheaper than buying them from the factory. He bought all the transistors needed. Cray carefully used these defective transistors to design a highly fault-tolerant circuit and succeeded, proving that those below-standard devices were carefully designed to achieve the desired goals of the computer. He built the first-rate computer with the "cheap" transistors that produced the radio. 1604 was the first fully transistorized large-scale scientific computer, which defeated IBM computers based on punched cards. [4]

Cray went to build a larger and faster scientific computer as soon as possible. It was the CDC6600. CDC6600 was 
developed in 1957 according to the secret order of the American Atomic Energy Commission. It was the fastest scientific computer in the world when it was launched in 1964, and it had a great influence in the history of computer development. It had reached the processing capacity of 1 MFLOPS for the first time, so it was widely regarded as the first supercomputer. [5]

It had many innovations in technology: the instruction system was very simple; the operation-oriented register had an 8-bit instruction buffer of 8 words each, which could store 16-32 instructions, including loop instruction segments, without accessing main memory; the simplified core processor had 10 operating components and a leading control component called "scoreboard" for parallel operation; core memory consisting of 32 modules with $4 \mathrm{~K}$ words could be cross-accessed; Supporting the CPU were ten peripheral processors that handled input and output, as well as controlling what data was sent into the main CPU for processing. [6]

The CDC6600 was three times faster than the previous record-holder, the IBM 7030 Stretch, but the price is lower. So it was well received by the market. [7] The design, development and production of the CDC6600 had achieved great success. Not only were many machines installed in scientific research units such as the National Laboratory of the United States, but they had exerted tremendous computing power, greatly promoted the advancement of science and technology. This was the first of what later came to be called reduced instruction set computer (RISC) design. It had also played a significant role in promoting the generation and development of super-scalar technology.

With performance of up to 3 MFLOPS, the CDC 6600 was the world's fastest computer from 1964 to 1969 , when it relinquished that status to its successor, the CDC 7600. On the basis of the CDC6600 architecture, Cray adopted a high-speed circuit with a gate-level delay of $1.5 \mathrm{~ns}$, and developed the CDC7600 with a computing speed of 15 million times per second. It became the world's highest performing computer in the early 1970 s.

The big customers such as the Los Alamos National Laboratory and the Lawrence Livermore National Laboratory, were urgently needed for powerful and high-performance computers. However, for the general users, the supercomputer was too high, and the price was prohibitive. it was also difficult to bear in financial resources. Therefore, the application field of the supercomputer was narrow, and the sales volume was limited. In 1972, the market for large scientific computers became smaller. CDC intended to suspend its efforts in this field, but Cray insisted that the market would thrive. Then, Cray left CDC, opened up his own business, and founded Cray Research Inc. (CRI)

\section{The Cray-Supercomputers}

The 1970-1980s ushered in the soaring period of supercomputers.

During the Cold War, in order to win an arms race with the
Soviet Union, the United States vigorously developed high-tech technologies such as strategic nuclear weapons and aerospace, all of which involved massive scientific and engineering calculations. Although IBM, UNIVAC, and CDC had provided some supercomputers, they still couldn't meet the needs of the US government and his military. [8] Approved by the Defense Advanced Research Projects Agency, the University of Illinois and Burroughs researched a supercomputer ILLIAC-IV in 1972. The scalar speed was up to an astonishing 150 million times per second. Texas Instruments and CDC had also introduced supercomputers TI-ASC and STAR-100 with a computing speed of more than 100 million operations per second. However, the common shortcoming of these three machines was that the system was large and cumbersome, the high speed was not sustainable, the actual efficiency was low, the power consumption was huge, and it was very inconvenient to use. For example, ILLIAC-IV was unstable for a long period of time after being delivered to the National Aeronautics and Space Administration (NASA). In 1975 , it was necessary to carry out a major inspection of the shutdown. It took ten months, from logic design to process manufacturing, to find thousands of faults and hidden dangers, and replace 110,000 system resistors. [9]

At this time, Cray also aimed at the development of a new generation of supercomputers. He built his company in Chippewa Falls. Without factory and workers, he began to design the first machine. It was also manufactured by a local electronics contractor. Seven of the company's 12 founders were from $\mathrm{CDC}$, and Cray was the chairman. The company only produced supercomputers. In order to solve the funding problem, some business owners who supported Cray jointly sent a proposal to Wall Street, and the results were so successful that Cray Research forced to IPO though they did not have sales, no turnover, or even a project but have 2400000 dollars deficit and only 8 potential users. The initial 6,000 shares immediately raised $\$ 10$ million, laying the material foundation for the development of new machines.

Competitors such as CDC used multiprocessor systems to build supercomputers, which interconnected multiple scalar processors to solve a problem. However, the scheduling and synchronization of multiple processors was a difficult problem. Cray had taken a different approach. He found that the characteristics of numerical weather forecasting, spacecraft design and nuclear physics research using supercomputers were a large number of vector operations. He used a vector processing method, which was realized by using multiple independent components. Parallel operations were transformed into streams that made them into a vector pattern, combined with a pipeline structure to achieve high parallelism of operations. In 1972, he personally designed and developed a vector supercomputer, named after his own name, called Cray-1.

Cray-1 had developed the success of the CDC6600 and CDC7600 machines with a range of innovative technologies such as vector data types and vector operations, ECL high-speed integrated circuits, vector registers, vector link technology, high-density assembly technology and efficient 
cooling technology, etc. It also changed the traditional cubic form of the supercomputer by using a cylindrical structure. The style was simple, beautiful and generous. Cray-1 was successfully developed in 1975 and was rigorously tested at the Los Alamos National Laboratory. It was officially launched in 1976 and could perform 136 million floating-point operations per second (136 mega-flops).

Cray-1 was the first supercomputer to use integrated circuits. There were only 4 ECL integrated circuits in the whole machine. It had 8 64-bit vector registers and backup register $\mathrm{B}, \mathrm{T}$. The main memory capacity was 2-8 megabytes. 12 full-streaming functional components could perform register-oriented vector and scalar operations in a highly parallel manner. Instruction format was regular, only 16-bit and 32-bit. There was a 4-page instruction buffer station that could store 256 short instructions or 128 long instructions, so that general cyclic program instructions or common sub-programs could be stored in the instruction buffer station without having to repeatedly access the main memory to ensure high-speed operation of the program. In addition, several related vector operation instructions could make the pipeline link run, which greatly improved the parallelism of vector operations. In addition to the hardware, it also equipped with FORTRAN language, COS operating system and the library software.

Cray-1 had several new features: (1) vector operations. For instance, it was able to add two sets of 64 pairs of operands, yielding 64 results, which could be seen as the result of executing only one instruction. (2) Pipeline processing. It meant that the functions of the computer were divided into stations, so that the instructions could be distributed and executed. For example, 64 additions were not performed at the same time, but were performed in a pipelined manner, and flowed out at a speed of one clock per clock cycle of the machine until 64 results ended. (3) Cylindrical cabinet structure. It had a total of 12 wedge-shaped frames, arranging in a 270-degree circular arc column, as a whole with a huge letter " $\mathrm{C}$ " (the initials of the Cray name), so that the interconnecting wires on the inner floor of the cylinder achieved the shortest. It ensured that the $80 \mathrm{MHz}$ clock frequency (the highest clock frequency in the world at that time) was realized. The floor space was only about 8 square meters, which was one-twentieth of TI-ASC and STAR-100. (4) Freon liquid cooling technology. This was a patent of Cray-1. In the middle of the aluminum frame with circuit board, there were many serpentine cooling pipes connected with the underground freon liquid device in order to solve the heat problem of the computer, which was assembled such high density.

Cray-1 had high performance, peak vector operation speed of 240 million floating point operations per second, and scalar operation speed of up to 50 million times per second, which was significantly better than ILLIAC-IV, TI-ASC and Star-100. Its ability to solve problems in scientific computing was equivalent to 40 IBM 370 computers, but the price was the same as 5-8 million dollars, so it was highly accepted by the computer industry and super-computing users. Praised and widely welcomed, it had won the market for scientific computing and very large-scale data processing. By 1979, there were 16 Cray- $1 \mathrm{~s}$. The simplicity and novelty of the Cray-1 architecture had in fact become the standard model for international vector supercomputers. Later, a lot of supercomputers based on Cray-1 were developed and produced in many countries. The architecture of China's first supercomputer YH-1, which was developed in 1978, mainly drew on the design idea of Cray-1. [10]

Next, Cray designed and developed a series of supercomputers with higher performances such as Cray-2, Cray- 3 and Cray-4, etc.

Cray-2 was a four-vector-processors system. The single processor basically retained the structure of Cray-1. It adopted a 16-gate array chip with a gate-level delay of 0.3-0.5 ns. The cycle was always $4.1 \mathrm{~ns}$ and the main memory capacity was 2048 megabytes. The instruction buffer station had doubled from Cray-1, increasing to 8 pages, and a local memory with a capacity of 128 bytes had been added. Cray-2 was successfully developed in 1985 . When the main memory used dynamic memory chips, the system peak processing speed was 1.8 billion floating point operations per second (1.8 Gigaflops). More than 10 times faster than Cray-1, it was first installed in the NASA to simulate the super-large wind tunnel experiment of the space shuttle. In the mid-1980s when Cray-2 was successfully produced, Cray Research's supercomputer once accounted for $70 \%$ of the global market.

The Cray-3 born in 1988, was an eight-vector processor system that used ECL and 300-500 gates/chip of GaAs logic chips and $1 \mathrm{~K}$-bit GaAs static memory chips (for registers) to make Cray-3's clock frequency up to $500 \mathrm{MHz}$. The peak performance was up to 6-10 Gigaflops. Although the machine was successfully developed, Cray Research met some commercial problems. Cray-3 was never sold.

In 1989, due to differences in management opinions, Cray left his own Cray Research Company and opened the CCC (Cray Computer Corporation) in Colorado. He began to fully invest in his Cray-4 development project. The clock frequency is doubled compared to Cray-3. All of it used GaAs circuits, and the speed was expected to exceed 100 billion times per second. Unfortunately, Cray-4 did not finish. [11]

The end of the Cold War meant that the government's budget cut. Coupled with the gradual boom in the PC market, supercomputer sales plummeted. In 1995, CCC was forced to declare bankruptcy under financial pressure. In 1996, Cray challenged again and set up the SRC (Seymour Roger Cray). He started the research and development of a new generation of large-scale super parallel computers. [12] However, the fate suddenly came at this time: At 3 pm on September 22th, 1996, Cray drove the car out of Colorado. When driving to the I-25, there were two cars in the back. One of them was dodging and suddenly hit the car of Cray. His car rolled over and fell to the side of the road. Cray's neck, ribs and head were seriously injured and were immediately taken to hospital for emergency treatment. In the end, due to the injury, at around 3 am on October 5th, Seymour Cray's heart stopped beating forever, at the age of 71. [13] 


\section{The Seymour Cray's Way}

In the development of supercomputers, Cray never felt that he was a pioneer. He said that he "is a nerd" and "only wants to be an engineer". [14] The key to success lies in his scientific thought and spirit. The main points are as follows:

(1) Adventure, innovation, and the pursuit of building the world's fastest supercomputer

Cray's several careers in his life were not simple, which was closely related to his dream of developing the supercomputer on top of the world. At ERA, Cray creatively designed his first computer ERA1103 with magnetic core memory, becoming the leader in the tube computer. When the company's development and his own goal of developing supercomputer gradually drifted away, he left at the risk of losing job and founded the CDC. The CDC1604 computer was the only fully transistorized computer in the world at that time. It also became the best commercial computer. After the success of CDC1604, Cray challenged the computer giant IBM and push the CDC6600 — the first supercomputer of the world before IBM's ambitious "360 Plan" (IBM360 achieves the world's fastest computer program). A scathing memo from IBM president Thomas Watson: "...they (CDC) officially announced their 6600 system...there are only 34 people (Cray's team), including the janitor...I fail to understand why we (IBM) have lost our industry leadership position by letting someone else offer the world's most powerful computer."[15] When the CDC executives satisfied with the CDC6600 and 7600 dominance market, Cray set up CRI again to continue building faster supercomputers and risking the greatest risk of failure. At that time, Fairchild co. Ltd, which just invented the integrated circuit, was still unclear what this device could do. Cray boldly applied integrated circuit technology to Cray-1 for the first time, making it the first machine that could sustain billions of super-computing. Although after Cray-2, Cray-3 and Cray-4 basically failed, the CCC later went bankrupt, SRC company was acquired, and he died in a car accident. However, Cray's spirit of "forever first" is constantly motivated the posterity.

(2) Simplicity the core design idea of the supercomputer system structure

The simplicity of the computer architecture was an important design idea that Cray had always adhered to, and it was fully reflected in the various generations of computer products he developed. Cray believed that in the computer world most people could design a good CPU, but very few people could create a nice architecture. The original 1103 machine was produced under this guidance. it was extremely simple and did not contain any unnecessary things. In the commercial competition, Cray always adhered to the principle of simplicity. Even before the RISC (Reduced Instruction Set Computer), which was popular in the world in the 1980s, he proposed and adopted a design concept similar to RISC. Simple was beauty. He once said: "My guiding ideology is simplicity. Don't put any extra things in unnecessary places, so you can design the computer as simple as possible", "I think I am a RISC person at any moment. Even when I still don't know when IBM created this term", "back to the most basic, make the machine as efficient and streamlined as possible", "I design the computer is like designing a sailboat, trying to make it simple." [16] The Cray series of supercomputers took Cray's succinct ideas to the extreme, and he independently designed all the hardware and operating systems.

(3) The methodology for creating new supercomputers

Cray had his own new computer methodology. He thought that insight came from customers. In the past three or four decades, many of his innovations had come from users. He obtained feedback from customers who used previous machines, and studied their complaints and demands. He summarized lessons, found some innovative ideas and considered how to use them in his next design. For Cray, the design process of an engineering project plan was very important. The basic concept of design was his, but he needed supporters to achieve his ideals. Cray believed that this was the only way to accomplish tasks efficiently and correctly. Once a task was completed and affirmed, another new plan could begin. When designing the basic part of a new computer, his method was to ask some questions at first, such as "What is the computer's instruction system?", "What is the storage capacity of the memory?", "What is the memory used for?" Once these issues were identified, he thought it would be time to start building the computer.

(4) Eliminate all interferences and focus on your favorite supercomputer research work

Cray had always been obsessed with the electrical equipment since he was a child. When reviewing he was criticized in the high school because he didn't seem to want to get in touch with everyone, Cray once ridiculed himself: "At that time, I spent all my time in the electrical engineering laboratory. I really didn't have enough energy to participate in social activities. "[17] When CDC6600 was developed, Cray led more than 30 people to hide in the depths of the jungles of Wisconsin. For more than four years, he did not come out to participate in any social activities. He buried his head to develop supercomputers. Even international academic institutions gave him awards, but Cray did not want to go to attend. As the company's second-in-command, Cray only went to the headquarters several times a year, even the company's CEO could only see him twice a year if he had an appointment. There were also times when very important high-level officials could personally rush to the Chippewa Falls in the jungle to listen to the Cray's lecture. After the meeting, they went to the local snack bar to have a drink, and Cray always rushed back to work only eating a hot dog. So, Cray won the nickname "The Jungle Hermit." When developing Cray-1, Cray and his assistants worked in the lab for hours in the afternoon, and went home at $4 \mathrm{pm}$, and at night he returned to the company alone until the next morning. After Cray-1's success, Cray felt that the growing popularity was not a good thing. Excessive administrative affairs and social activities prevented him from focusing on his goals. Cray simply gave the chairman's position to the company's president. He only retained the identity of the board of directors and became the company's only research and 
development contractor. He could concentrate on it. Cray always declined the invitational lectures of various scientific business groups. He did not receive a reporter during the entire 1976-1981. Cray also rarely let the company's staff visit him, and he did not like to answer the phone every afternoon. In Cray's words, he could focus on the "things" of the computer, not the "human" part.

In 1976, after a rare speech at the National Center for Atmospheric Research in Colorado, programmers in the audience had suddenly fallen silent when Cray agreed to answer questions. He stood on the podium for a few minutes, waiting for their queries, but none came. After Cray left, the head of NCAR's computing division chided the listeners: "Why didn't you raise your hand to ask?" After a tense moment, one programmer replied: "How do you talk to God?" [18]

This is Seymour Cray.

\section{References}

[1] Tribute to Seymour Cray. IEEE Computer Society. Archived from the original on 2010-8-24.

[2] Murray, Charles J. The Supermen: The Story of Seymour Cray and the Technical Wizards Behind the Supercomputer, John Wiley \& Sons, 1997, pp. 47.

[3] Weik, Martin H. (June 1957). "UNIVAC SCIENTIFIC 1103". ed-thelen.org. A Second Survey of Domestic Electronic Digital Computing Systems.

[4] Control Data Corporation. CDC 1604 Computer, Vol 1: Description and Operation, 1960, pp. 1-1.

[5] Making a World of Difference: Engineering Ideas into Reality, National Academy of Engineering, 2014, pp. 6.
[6] Hu Shouren. History of computer technology, National University of Defense Technology Press, Changsha, 2016, pp. 86.

[7] Chen Houyun, Wang Xinggang. The growth of computers: a History of computer Development in the 1960s, Journal of Dialectics of Nature, 1980, Vol 6: pp. 59-60.

[8] Si Hongwei, Feng lisheng. Research on the innovation and development of supercomputer, Scientific Management Research, 2017, Vol 35: pp. 118.

[9] Wang Xinggang, Chen Houyun. History of computer Development in the 1970s, Journal of Dialectics of Nature, 1982, Vol 4: pp. 55.

[10] Si Hongwei, Feng lisheng. The Development of the First Supercomputer YH-1 in China and Its Inspiration, Studies in the History of Natural Sciences, 2017, Vol 36: pp. 566.

[11] Charles W. Breckenridge. A Tribute to Seymour Cray. the keynote session at Supercomputing 96, 1996-11-19.

[12] John Markoff. Computer Whiz Seymour Cray, New York Times, 1996-10-6.

[13] Computer pioneer Cray hurt. The Journal Times (Colorado Springs). 1996-9-23.

[14] Toby Howard. Seymour Cray: An Appreciation. Personal Computer World magazine, 1997, Vol 2: pp. 1.

[15] Bell, Gordon. A Seymour Cray Perspective. Microsoft Research. http://www.si.edu/resource/tours/comphist/cray.htm. 1997-9-10.

[16] William D. Metz. Midwest Computer Architect Struggles with Speed of Light. Science, vol 199, 1978 (1): 404-409.

[17] Seymour Cray Oral History, University of Minnesota, Babbage Institute, 1996.

[18] Fang Xingdong, Superman: legend of Seymour Cray, China Computer World, 2004-10-11. 